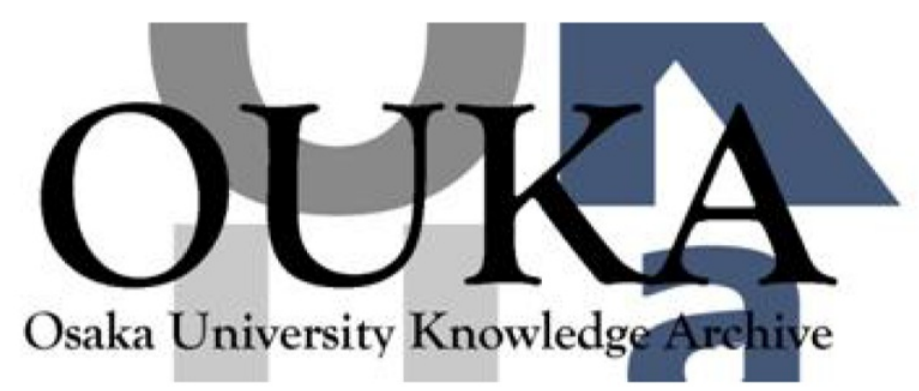

\begin{tabular}{|c|l|}
\hline Title & $\begin{array}{l}\text { In Situ ECAFM Observation on Pb Electrodes in } \\
\text { Sulfuric Acid Solution with or without Lignin }\end{array}$ \\
\hline Author(s) & $\begin{array}{l}\text { Tabayashi, Daiji; Hirai, Nobumitsu; Shiota, } \\
\text { Masashi et al. }\end{array}$ \\
\hline Citation & AIP Conference Proceedings. 696 p. 502-p. 507 \\
\hline Issue Date & $2003-07$ \\
\hline oaire:version & VoR \\
\hline URL & https://hdl.handle.net/11094/26530 \\
\hline rights & 02003 American Institute of Physics \\
\hline Note & \\
\hline
\end{tabular}

Osaka University Knowledge Archive : OUKA

https://ir. Library. osaka-u. ac. jp/

Osaka University 


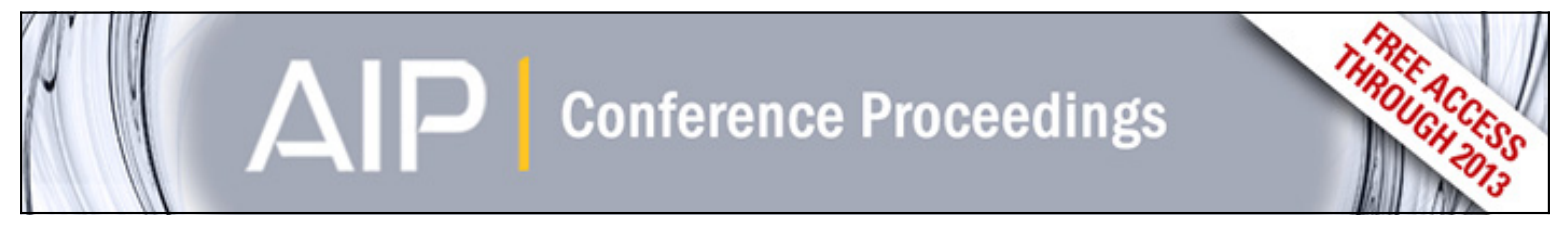

In Situ ECAFM Observation on Pb Electrodes in Sulfuric Acid Solution with or without Lignin

Daiji Tabayashi, Nobumitsu Hirai, Masashi Shiota, and Toshihiro Tanaka

Citation: AIP Conference Proceedings 696, 502 (2003); doi: 10.1063/1.1639743

View online: http://dx.doi.org/10.1063/1.1639743

View Table of Contents: http://scitation.aip.org/content/aip/proceeding/aipcp/696?ver=pdfcov

Published by the AIP Publishing 


\title{
In Situ EC-AFM Observation on Pb Electrodes in Sulfuric Acid Solution with or without Lignin
}

\author{
Daiji Tabayashi $^{\mathrm{a}}$, Nobumitsu Hirai ${ }^{\mathrm{a}^{*}}$, Masashi Shiota $^{\mathrm{b}}$, Toshihiro Tanaka ${ }^{\mathrm{a}}$ \\ ${ }^{a}$ Department of Materials Science and Processing, Graduate School of Engineering, Osaka University, \\ Yamadaoka 2-1, Suita, Osaka 565-0871, Japan \\ ${ }^{b}$ Yuasa Corporation, 2-3-21 Kosobe-cho, Takatsuki, Osaka 569-1115, Japan
}

\begin{abstract}
Surface morphologies of $\mathrm{Pb}$ electrodes in sulfuric acid solution with or without lignin at $-20^{\circ} \mathrm{C}$ during anodic oxidation have been investigated by using in situ EC-AFM combined with cyclic voltammetry (CV). Whether the lignin is added or not in the solution, it was found at $-20^{\circ} \mathrm{C}$ that the precipitation of lead sulfate crystals occurs immediately after supersaturation of dissolved $\mathrm{Pb}^{2+}$ ions at the anodic oxidation peak on $\mathrm{CV}$. It was also found that the number of lead sulfate crystals formed on the $\mathrm{Pb}$ electrode after anodic oxidation decreases and the crystal size becomes larger when the lignin is added in the solution.
\end{abstract}

\section{INTRODUCTION}

Lead-acid battery is "old" because it was first developed in 1861 and it has been already used for power sources of automotive starters and uninterruptible power supplies all over the world. It is still "new", however, because new applications of this battery to power supply for hybrid cars, load-leveling systems, and so on, are strongly expected. It is indispensable to understand the reactions on electrodes of the battery in details during charging or discharging in order to construct a new battery, which is much smaller, much lighter, and has much longer lifetime, for the new applications [1].

Electrochemical atomic force microscopy (EC-AFM), as well as electrochemical STM, is one of powerful tools, by which we can observe in-situ electrode surfaces in electrolytes. Not only atomic or molecular arrangements on single crystals of electrode, but also morphology on electrode in a micron scale, can be observed by means of ECAFM. We have already succeeded in in-situ EC-AFM observation upon morphological change of on a $\mathrm{Pb}$ or $\mathrm{PbO}_{2}$ surface in sulfuric acid aqueous solution as a model of the negative or negative electrode of lead-acid batteries [2-8]. The observation gives interesting knowledge of electrochemical reactions on the electrodes in lead-acid batteries.

Lignin (lignosulphonate) is one of the popular additives for the negative electrode of the lead-acid battery. It is extracted from woods and is a kind of complex polymer substance. It is known that lignin improves the performance of the lead-acid battery, especially the discharge capacity at low temperature (e.g. $-20^{\circ} \mathrm{C}$ ), however, the

* Corresponding author; Tel \& Fax: +81-6-6879-7468, E-mail address; nhirai@mat.eng.osaka-u.ac.jp 
detailed mechanism of the effect of lignin from electrochemical point of view is still obscure.

In this paper, we present in-situ EC-AFM images on $\mathrm{Pb}$ electrodes in sulfuric acid solution with lignin at $-20^{\circ} \mathrm{C}$, and discuss the effect of lignin on the electrochemical reaction of $\mathrm{Pb}$ electrodes.

\section{EXPERIMENTAL}

\subsection{EC-AFM}

The schematic illustration of EC-AFM is shown in FIGURE 1. The EC-AFM is composed of an AFM (Pico SPM, Molecular Imaging Co.), a control unit (Pico Scan 2100, Molecular Imaging Co.), an electrochemical cell and some electrochemical devices. The electrochemical cell consists of a $\mathrm{Pb}$ electrode as the working electrode, a $\mathrm{PbO}_{2}$ electrode as the counter electrode, and a $\mathrm{Hg} / \mathrm{Hg}_{2} \mathrm{SO}_{4}$ as the reference electrode. All potentials reported here are referred to this potential. The electrochemical operations are carried out using a potentio/galvano stat (Model HZ-3000, Hokuto Denko Co). The sample temperature $\left(-20^{\circ} \mathrm{C}\right)$ is controlled by a Peltier device with a control unit (Model 321, Lake Shore Co). All experiments are carried out in a chamber filled with Ar gas to avoid the oxidation of the electrode.

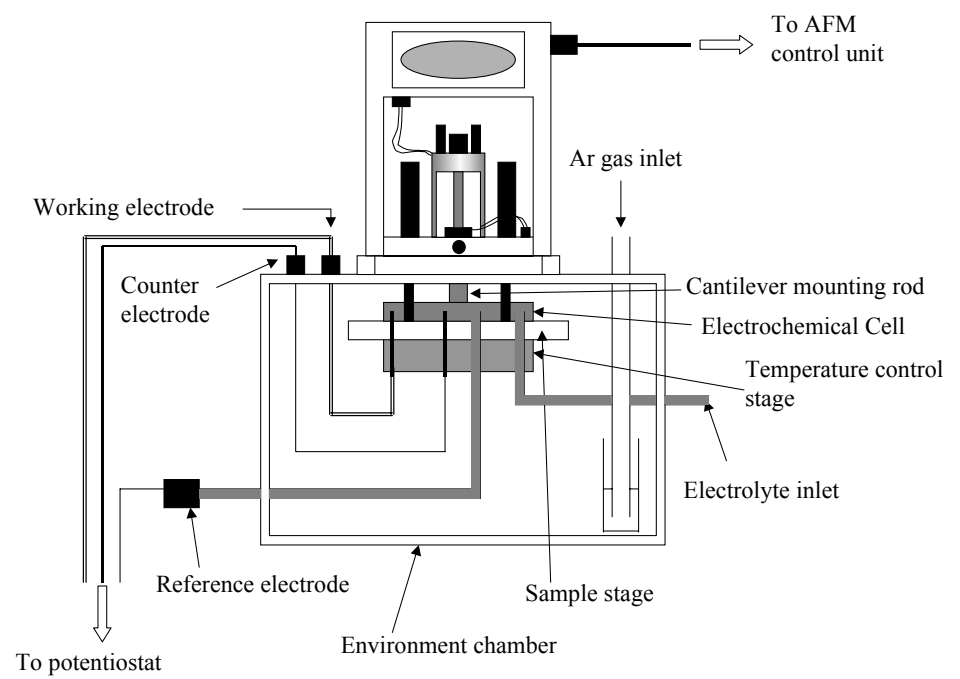

FIGURE 1. Schematic illustration of EC-AFM.

\subsection{Experimental preparation for EC-AFM and CV}

$\mathrm{Pb}$ electrodes (Sample 1 and 2) were prepared from pure $\mathrm{Pb}$ sheets $(99.99 \%$, Niraco Co). Before EC-AFM or cyclic voltammetry (CV), the Sample 1 was dipped in ultra pure water with 100ppm lignin for 2 hours in order to form the film containing $\mathrm{Pb}$ and lignin on the electrode surface [9]. The lignin used here is 'Vanillex N' (Nippon Paper Industries Co.). Then, the electrolyte was replaced by $5 \mathrm{~mol}^{-1}$ sulfuric acid solution 
with 20ppm lignin. On the other hand, the Sample 2 was dipped in $5 \mathrm{~mol}^{-1}$ sulfuric acid solution without lignin. Immediately after the Sample 1 or 2 dipped in the electrolyte $\left(5 \mathrm{~mol} \mathrm{l}^{-1}\right.$ sulfuric acid solution with $20 \mathrm{ppm}$ lignin or without lignin), potential of $-1200 \mathrm{mV}$ was applied and kept for $30 \mathrm{~min}$ to reduce sufficiently lead oxide and/or lead sulfate on the electrode surface to $\mathrm{Pb}$. After this reduction, the temperature fell to $-20^{\circ} \mathrm{C}$. All experiments were performed at $-20^{\circ} \mathrm{C}$. An outline of experimental procedure is shown in FIGURE 2.

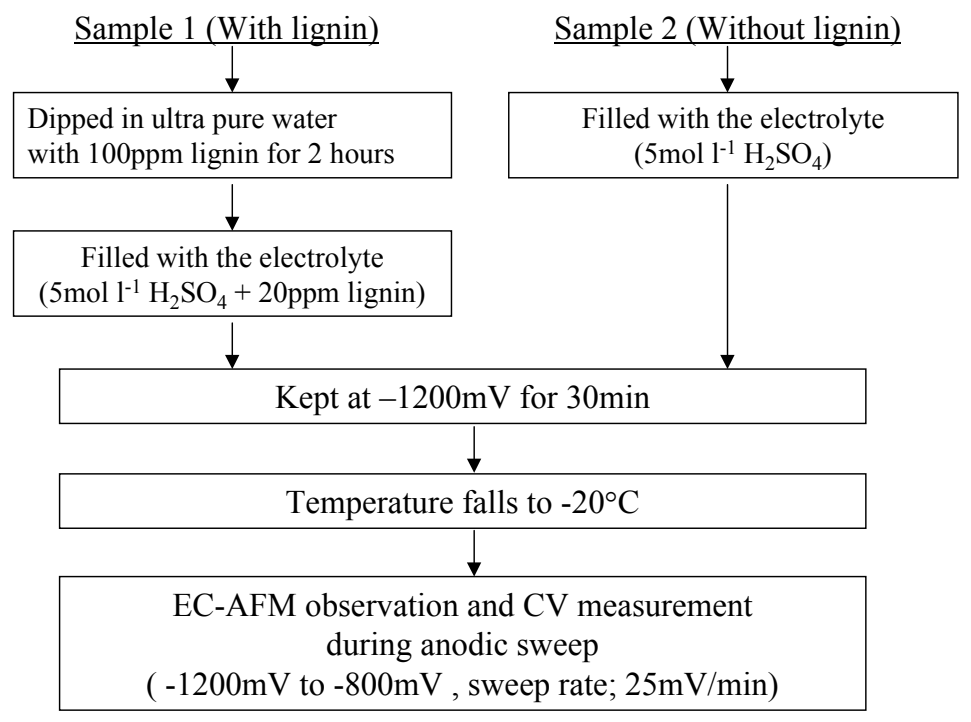

FIGURE 2. Experimental procedure for EC-AFM and CV.

\section{RESULTS AND DISCUSSION}

\subsection{Cyclic Voltammetry (CV)}

Cyclic Voltammograms of Sample 1 (in sulfuric acid solution with lignin; the broken line) and Sample 2 (in sulfuric acid solution without lignin the solid line) at $-20^{\circ} \mathrm{C}$ during anodic sweep from $-1200 \mathrm{mV}$ to $-800 \mathrm{mV}$ are shown in FIGURE 3. The potential sweeping rate is $25 \mathrm{mVmin}^{-1}$. The anodic current in the CVs corresponds to electrochemical reaction from $\mathrm{Pb}$ to lead sulfate $\left(\mathrm{Pb}+\mathrm{SO}_{4}{ }^{2-} \rightarrow \mathrm{PbSO}_{4}+2 \mathrm{e}^{-}\right)$. It was found that the anodic capacity for Sample 1 is about $160 \%$ larger than that for Sample 2. This result practically agrees with the fact that the discharge capacity (anodic capacity for negative electrodes) of lead-acid batteries increases with the addition of lignin.

\subsection{EC-AFM}

Before anodic sweep, the electrode surfaces in electrolyte were observed by ECAFM in order to make sure that no lead sulfate crystals were found on the surfaces. Then, surface morphologies of $\mathrm{Pb}$ electrodes in electrolyte during anodic sweep from $-1200 \mathrm{mV}$ to $-800 \mathrm{mV}$ have been investigated by using in situ EC-AFM. The potential 
sweeping rate is $25 \mathrm{mVmin}^{-1}$. Because the capturing rate was about $4 \mathrm{~min}$ per one AFM image, 4 of in situ EC-AFM images $(10 \mu \mathrm{m} \times 10 \mu \mathrm{m})$ could be captured during one anodic sweep.

FIGURES 4 and 5 show the in situ EC-AFM images $(10 \mu \mathrm{m} \times 10 \mu \mathrm{m})$ for Sample 1(with lignin) and Sample 2 (without lignin), respectively. From EC-AFM images and CVs, it was found for both Sample 1 and Sample 2 that little morphological changes are observed until the anodic current reaches the maximum of the peak, while a lot of lead sulfate crystals deposits immediately after the anodic current has crossed the

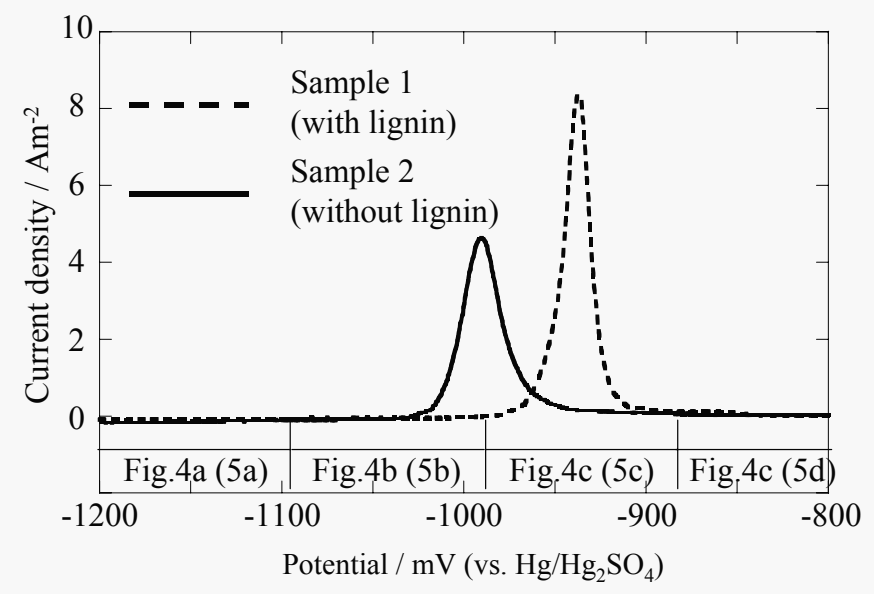

FIGURE 3. Cyclic Voltammograms of Sample 1 in $5 \mathrm{~mol}^{-1}$ sulfuric acid solution with 20ppm lignin (the broken line) and of Sample 2 in $5 \mathrm{~mol}^{-1}$ sulfuric acid solution without lignin (the solid line) at $-20^{\circ} \mathrm{C}$ during anodic sweep from $-1200 \mathrm{mV}$ to $-800 \mathrm{mV}$. The potential sweeping rate is $25 \mathrm{mVmin}^{-1}$.

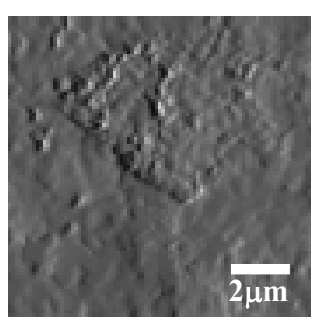

(a) $-1200 \mathrm{mV} \rightarrow-1100 \mathrm{mV}$

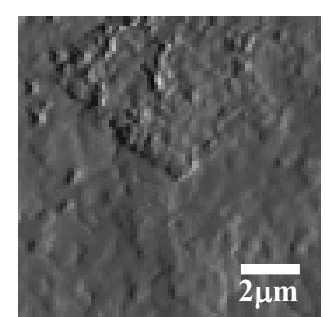

(b) $-1095 \mathrm{mV} \rightarrow-995 \mathrm{mV}$

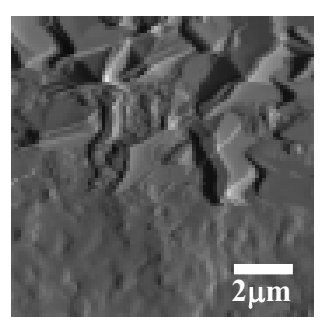

(c) $-990 \mathrm{mV} \rightarrow-890 \mathrm{mV}$

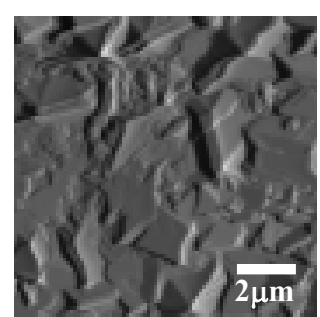

(d) $-885 \mathrm{mV} \rightarrow-785 \mathrm{mV}$

FIGURE 4. Continuous in-situ EC-AFM images of Sample 1 (in $5 \mathrm{~mol}^{-1}$ sulfuric acid solution with 20ppm lignin) at $-20^{\circ} \mathrm{C}$ during anodic sweep from $-1200 \mathrm{mV}$ to $-800 \mathrm{mV}$. The potential sweeping rate is $25 \mathrm{mVmin}^{-1}$.

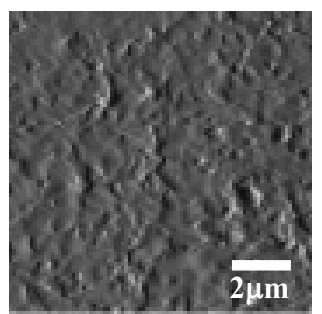

(a) $-1200 \mathrm{mV} \rightarrow-1100 \mathrm{mV}$

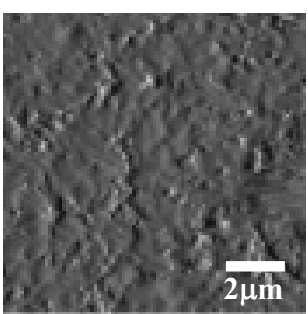

(b) $-1095 \mathrm{mV} \rightarrow-995 \mathrm{mV}$

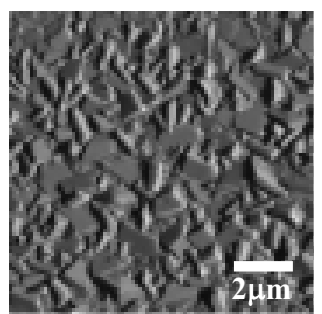

(c) $-990 \mathrm{mV} \rightarrow-890 \mathrm{mV}$

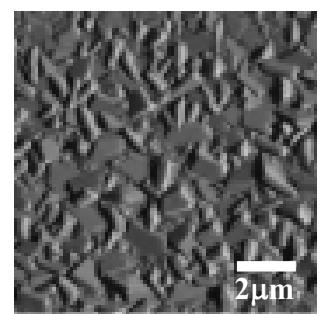

(d) $-885 \mathrm{mV} \rightarrow-785 \mathrm{mV}$

FIGURE 5. Continuous in-situ EC-AFM images of Sample 2 (in $5 \mathrm{~mol}^{-1}$ sulfuric acid solution without lignin) at $-20^{\circ} \mathrm{C}$ during anodic sweep from $-1200 \mathrm{mV}$ to $-800 \mathrm{mV}$. The potential sweeping rate is $25 \mathrm{mVmin}^{-1}$. 
maximum of the peak. In our early work [3], it was visually confirmed in the solution without lignin at room temperature that $\mathrm{Pb}$ dissolves during the anodic oxidation $\left(\mathrm{Pb} \rightarrow \mathrm{Pb}^{2+}+2 \mathrm{e}^{-}\right)$, followed by the precipitation of $\mathrm{PbSO}_{4}$ crystals immediately after the supersaturation of the dissolved $\mathrm{Pb}^{2+}$ ions $\left(\mathrm{Pb}^{2+}+\mathrm{SO}_{4}{ }^{2-} \rightarrow \mathrm{PbSO}_{4}\right)$. These processes are called "solution-precipitation mechanism" [10]. FIGURES 3-5 show that the $\mathrm{PbSO}_{4}$ is formed mainly by the solution-precipitation mechanism on $\mathrm{Pb}$ electrodes at $-20^{\circ} \mathrm{C}$, whether the lignin is added or not in the solution.

From FIGURES 4 and 5, it was also found that the number of lead sulfate crystals formed on the $\mathrm{Pb}$ electrode after anodic oxidation decreases and the crystal size becomes larger when the lignin is added in the solution. FIGURE 6 shows the schematic illustration of the cross section near the electrode surface. FIGURE 6a and $6 \mathrm{~b}$ are for the Sample 1 and the Sample 2, respectively. The larger crystal size with the addition of lignin practically agrees with the experimental results that the anodic capacity of $\mathrm{CV}$ becomes larger when the lignin is added in the solution, as already shown in FIGURE 3. We consider that the increase of the number of crystals with the addition of lignin can be explained by the decrease of the density of nuclei. The density of 3 dimensional critical nuclei $N^{*}$ can be described by the following equation;

$$
N^{*} \propto \exp \left(-\Delta G^{*} / k T\right)=\exp \left[\frac{-\pi\left(2 \gamma_{P_{B S O} O_{4}}+\gamma_{I}-\gamma_{S}\right)^{3}}{3 k^{3} T^{3} n_{0}^{2}(\log (1+\sigma))^{2}}\right]
$$

where $\Delta G^{*}$ the Gibbs free energy of a critical nucleus, $\gamma_{\mathrm{PbSO}_{4}}$ the surface tension of lead sulfate, $\gamma_{I}$ the interfacial tension between lead sulfate and the substrate, $\gamma_{S}$ the surface tension of the substrate, $n_{0}$ the atomic density of $\mathrm{Pb}$ atoms in lead sulfate, and $\sigma$ the supersaturation, respectively. It is considered that $\gamma_{S}$ of Sample 1 is much smaller than that of Sample 2 because the surface of Sample 1 is covered by lignin. Therefore, $N^{*}$ of Sample 1 is considered to be much smaller than that of Sample 2. This consideration practically agrees with the EC-AFM images.

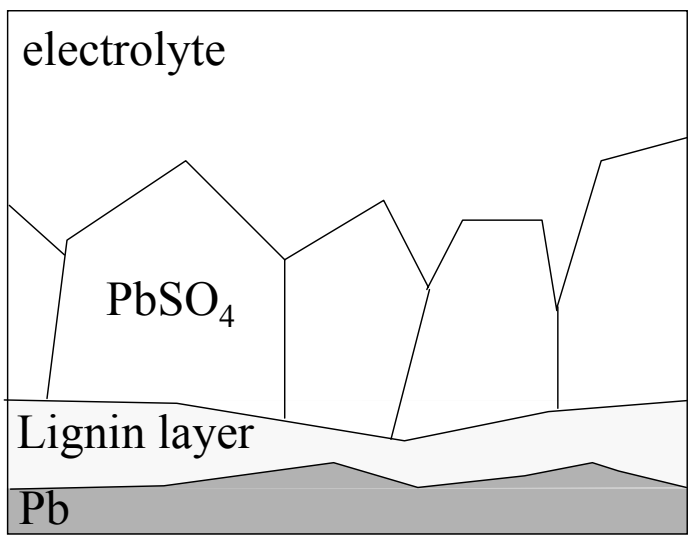

(a)Sample 1

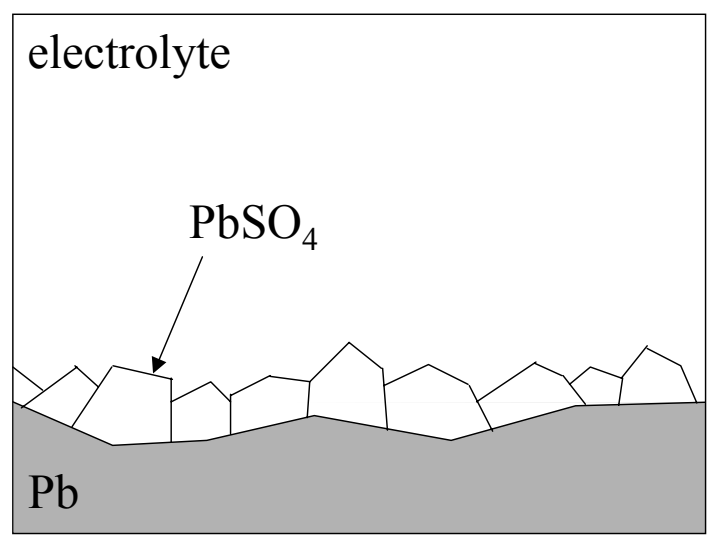

(b)Sample 2

FIGURE 6. Schematic illustrations of the cross section near the electrode surface after anodic oxidation. 


\section{CONCLUSION}

Electrochemical behavior of $\mathrm{Pb}$ electrodes in $5 \mathrm{~mol} \mathrm{l}^{-1}$ sulfuric acid solution with 20 ppm lignin or without lignin at $-20^{\circ} \mathrm{C}$ during anodic oxidation from $-1200 \mathrm{mV}$ to $800 \mathrm{mV}$ has been investigated by in situ EC-AFM and CV. Whether the lignin is added or not in the solution, it was found that the precipitation of lead sulfate crystals occurs immediately after supersaturation of dissolved $\mathrm{Pb}^{2+}$ ions at the anodic oxidation peak on cyclic voltammogram $(\mathrm{CV})$ also at $-20^{\circ} \mathrm{C}$. It was also found that the size of lead sulfate crystals formed on the $\mathrm{Pb}$ electrode after anodic oxidation becomes larger when the lignin is added in the solution.

\section{ACKNOWLEDGMENTS}

The authors express their sincere thanks to Prof. Shigeta Hara of Osaka University and Ms. Ikumi Ban of Yuasa Corporation for detailed discussion in this work. This study was partly supported by Industrial Technology Research Grant Program (ID number: 01B60015C) in 2001-2003 from New Energy and Industrial Technology Development Organization (NEDO) of Japan.

\section{REFERENCES}

1. Rand, D. A. J., Boden, D. P., Lakshmi, C. S., Nelson, R. F., and Prengaman, R. D., J. Power Sources 107, 280-300 (2002).

2. Yamaguchi, Y., Shiota, M., Nakayama, Y., Hirai, N., and Hara, S., J. Power Sources 85, 22-28 (2000).

3. Yamaguchi, Y., Shiota, M., Nakayama, Y., Hirai, N., and Hara, S., J. Power Sources 93, 104-112 (2001).

4. Shiota, M., Yamaguchi, Y., Nakayama, Y., Adachi, K., Taniguchi, S., Hirai, N., and Hara, S., J. Power Sources 95, 203-208 (2001).

5. Yamaguchi, Y., Shiota, M., Nakayama, Y., Hosokawa, M., Hirai, N., and Hara, S., J. Power Sources 102, 156$162(2001)$.

6. Ban, I., Yamaguchi, Y., Nakayama, Y., Hirai, N., and Hara, S., J. Power Sources 107 167-172 (2002).

7. Shiota, M., Yamaguchi, Y., Nakayama, Y., Hirai, N., and Hara, S., J. Power Sources 113 277-280 (2003).

8. Hirai, N., Takeda, K., Hara, S., Shiota, M., Yamaguchi, Y., and Nakayama, Y., J. Power Sources 113 329-334 (2003).

9. Saito, K., Hirai, N., Shiota, M., Yamaguchi, Y., and Nakayama, Y., and Hara, S., J. Power Sources in press.

10. Archdale, G., and Harrison, J. A., J. Electroanal. Chem. 39 357-366 (1972). 